\title{
Remoção biológica de fósforo em reatores em bateladas sequenciais com diferentes tempos de retenção de sólidos
}

\section{Biological phosphorus removal in sequencing batch reactors with different solid retention times}

\author{
Israel Nunes Henrique \\ Mestre em Desenvolvimento e Meio Ambiente pelo Programa Regional de Pós-Graduação em Desenvolvimento e Meio Ambiente (PRODEMA) da \\ Universidade Federal da Paraíba (UFPB) e Universidade Estadual da Paraíba (UEPB). Doutorando em Recursos Naturais pela Universidade Federal de \\ Campina Grande (UFCG)

\section{José Tavares de Sousa} \\ Mestre em Engenharia Civil pela UFPB. Doutor em Hidráulica e Saneamento pela Universidade de São Paulo (USP). Professor da UEPB. Coordenador do \\ Mestrado em Ciência e Tecnologia Ambiental da UEPB
}

\section{Beatriz Susana Ovruski de Ceballos}

Mestre em Microbiologia e Imunologia pela Universidade Federal de São Paulo (Unifesp). Doutora em Ciências Biológicas pela USP. Professora da UEPB

\section{Danielle Patrício Brasil}

Mestranda em Ciência e Tecnologia Ambiental pela UEPB

\section{Resumo}

Nos últimos anos, tem surgido a necessidade de se projetarem sistemas de tratamento de águas residuárias que, além de remover carga orgânica, sejam capazes de remover nutrientes, particularmente nitrogênio e fósforo. Este trabalho avaliou a remoção biológica de fósforo em sistemas de lodo ativado, tratando esgoto doméstico por meio de reatores em bateladas sequenciais (RBS), monitorado com diferentes tempos de retenção celular (TRC): 20, 5 e 3 dias. Esses experimentos foram avaliados em escala de bancada com o uso da respirometria, utilizando-se acetato como fonte de carbono orgânico. Os resultados mostraram satisfatória remoção de fósforo total nos três experimentos, com valores médios entre 79 a 82\%, sendo que o sistema RBS que operou com TRC de cinco dias obteve resultados melhores.

Palavras-chave: remoção biológica de fósforo; tempo de retenção celular; reator em batelada sequencial.

\begin{abstract}
In recent years, there has been an increasing need to design wastewater treatment systems that are capable of removing both organic material and nutrients, notably nitrogen and phosphorus. This study evaluated biological phosphorus removal by activated sludge systems fed with domestic sewage and operating as sequencing batch reactors (SBR) with different solids retention times (SRT) namely 20, 5 and 3 days. This was supported by respirometry experiments at bench scale using acetate as the source of organic carbon. The results showed satisfactory total phosphorus removal efficiencies mean values between $79-82 \%$ for the three regimes with the best removal efficiency occurring in the SBR operating with a five-day SRT.
\end{abstract}

Keywords: biological phosphorus removal; sludge retention time; sequencing batch reactor. 


\section{Introdução}

A remoção de fósforo e nitrogênio no processo de tratamento de esgotos busca diminuir o impacto eutrofizante dos lançamentos dos efluentes nos corpos aquáticos. A redução de apenas nitrogênio não é ambientalmente eficiente porque diversas bactérias, cianobactérias e algas podem fixá-lo da atmosfera e oxidá-lo em nitrito e nitrato. A remoção de fósforo durante o tratamento é, portanto, mais efetiva na atenuação da eutrofização. Em consequência, os sistemas de tratamento de esgotos devem remover quantidades significativas de fósforo, reduzindo-os aos níveis mais baixos possíveis.

Sendo assim, para que tal inibição ocorra, há necessidade de uma remoção eficiente do fósforo (WENTZEL et al, 1989). Reduzir concentrações de fósforo para níveis mais baixos possíveis é vital para evitar eutrofização dos sistemas aquáticos.

Atualmente, prefere-se a remoção biológica de fósforo à precipitação química, sobretudo se o processo for de baixo custo e apresentar remoção satisfatória, atendendo aos padrões de lançamento exigidos pela legislação (SIDAT; KASAN; BUX, 1999; Van DER POST; SCHUTTE, 2003).

As técnicas de remoção biológica de fósforo se baseiam na capacidade, de algumas bactérias heterotróficas presentes na biomassa ativa dos lodos ativados, de acumularem, dentro da célula, fosfato solubilizado na forma de polifosfatos, se houverem condições ótimas para seu crescimento e metabolismo (WANG et al, 2008).

A composição típica de fósforo, encontrada em tratamento de lodos ativados com bactérias heterotróficas presentes em lodos ativados, é de 1,5 a 2,0\% (METCALF; EDDY, 2003), chegando a casos de 2,5\% (Van HAANDEL; MARAIS, 1999).

As condições que levam ao enriquecimento de fósforo no lodo ativo têm sido objeto de estudo de diversas pesquisas e modelos conceituais nas últimas décadas. Como exemplo tem-se o modelo de Rensink (1981); Marais et al (1983); Comeau et al (1986); Abu-Ghararah e Randall (1989) e Wentzel et al (1986) (apud STENSEL, 1991).

Embora haja aspectos a serem resolvidos, a remoção biológica de fósforo apresenta pontos importantes como: a) o lodo ativo em

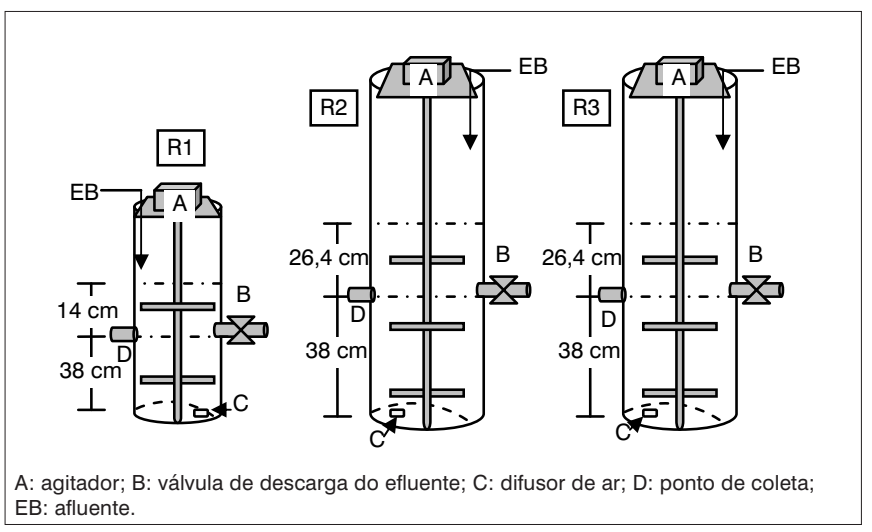

Figura 1 - Esquema dos reatores em bateladas sequenciais condições anaeróbias tende a liberar fosfato para a fase líquida se houver disponibilidade de substrato orgânico de fácil degradação. Sob essas condições, as bactérias poli-P usam a energia derivada da hidrólise dos polifosfatos para sequestrar substratos orgânicos que são armazenados na forma de polihidroalcanoatos (PHA), como poli- $\beta$-hidroxibutirato (PHB) ou poli- $\beta$-hidroxivalerato (PHV); b) em condições aeróbias, a energia derivada do metabolismo dos PHA é usada para a acumulação de polifosfato no interior da célula. A remoção biológica de fósforo envolve a sua incorporação na biomassa celular. A retirada de fósforo do sistema ocorre através do descarte da biomassa (WENTZEL et al, 1989; STENSEL, 1991; Van HAANDEL; MARAIS, 1999).

A concentração de sólidos suspensos no licor misto é uma medida bruta para caracterizar a concentração de bactérias envolvidas no processo. Teoricamente, quanto mais sólidos em suspensão no sistema, maior é a eficiência do processo, proporcionando maior remoção de demanda química de oxigênio (DQO) e nutrientes (SIDAT et al, 1999; WANG et al 2008).

A população de bactérias, que constituem a fração mais elevada de fósforo (20 a 30\% de massa seca em relação à fração de fósforo por sólidos suspensos voláteis de lodo ativado convencional), é denominada bactérias poli-P ou organismos acumuladores de fósforo (OAF) (METCALF; EDDY, 2003).

Nesta pesquisa, são relatados resultados de experimentos efetuados com reatores em bateladas sequenciais, aplicando-se diferentes tempos de retenção celular (TRC) para remoção de fósforo em diferentes concentrações de lodo, para verificar a eficiência de remoção de fósforo, utilizando-se dois tipos de afluentes: sintético e esgoto bruto doméstico.

\section{Metodologia}

O experimento foi instalado e monitorado na Estação Experimental de Tratamento Biológico de Esgotos Sanitários (EXTRABES) no mu-

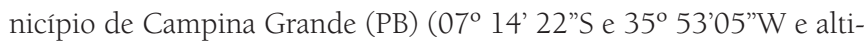
tude de $550 \mathrm{~m}$ ).

Os sistemas de tratamento, utilizados nesta pesquisa, foram reatores em bateladas sequenciais, construídos de PVC, com forma cilíndrica (Figura 1), tratando diferentes volumes de esgoto bruto doméstico, intercalando fases anaeróbias e aeróbias com baixa concentração de oxigênio dissolvido $\left(0,5\right.$ a $\left.1,2 \mathrm{mgO}_{2} \cdot \mathrm{L}^{-1}\right)$. Na Tabela 1 , são apresentados os parâmetros de monitoramento utilizados durante o período experimental.

\section{Metodologia da caracterização da remoção de fósforo}

Foram realizados testes no sistema experimental de reatores em batelada utilizando-se como fonte de carbono o esgoto bruto doméstico e testes de bancada com respirometria, e como substrato orgânico o acetato, com a adição de fósforo em solução. 
O respirômetro (Beluga) foi desenvolvido no Departamento de Engenharia Elétrica da Universidade Federal de Campina Grande (UFCG). O aparelho transmite os dados de leituras de Oxigênio Dissolvido (OD) $\left(\mathrm{mgO}_{2} \cdot \mathrm{L}^{-1}\right)$, temperatura $\left({ }^{\circ} \mathrm{C}\right)$ e a taxa de consumo de oxigênio (TCO) $\left(\mathrm{mgO}_{2} \cdot \mathrm{L}^{-1} \cdot \mathrm{h}^{-1}\right)$ para um microcomputador.

As análises físicas e químicas realizadas obedeceram às recomendações preconizadas pelo Standard Methods for the Examination of Water and Wastewater (APHA, 1998). As variáveis analisadas durante todo o monitoramento foram: pH, DQO, Sólidos Suspensos Totais (SST) e suas frações, fósforo total $\left(\mathrm{P}_{\text {total }}\right)$, ortofosfato $\left(\mathrm{P}^{-} \mathrm{PO}_{4}^{3-}\right)$ e nitrato $\left(\mathrm{N}^{3} \mathrm{NO}_{3}^{-}\right)$.

\section{Monitoramento in loco do teste no Reator 1}

O sistema no Reator 1 (R1) foi operado com distribuição de duas fases aeróbias intercaladas a uma fase anaeróbia com 15 minutos de alimentação na $1^{\mathrm{a}}$ e $2^{\mathrm{a}}$ fases (Figura 2). Os tempos foram assim distribuídos para favorecer a nitrificação na fase 1 (fase aeróbia) e a desnitrificação com liberação de fósforo na fase 2 (fase anaeróbia), e para que ocorresse a assimilação do fósforo na fase 3 (fase aeróbia).

\section{Monitoramento e distribuição de coletas para o teste in}

\section{loco nos Reatores 2 e 3}

Para cada ciclo, foram efetuadas quatro fases com duas repetições das fases anaeróbias e aeróbias, denominadas, respectivamente, fases 1, 2, 3 e 4, conforme Figura 3. A repetição dessas fases teve o objetivo de promover maior assimilação de fósforo e, portanto, buscou maior remoção.

A coleta das amostras nos reatores foi realizada em quatro fases:

a) Fase endógena: foi considerada no início de cada ciclo, entendendose que a curva de crescimento bacteriano encontrava-se na fase de respiração endógena. Nessa fase, foi coletada uma amostra inicial;

b) Fase de alimentação: teve duração de 45 minutos e as coletas de amostras foram feitas regularmente a cada 15 minutos;

c) Fase anaeróbia: compreendeu o período de 45 minutos da fase de alimentação, mais 60 minutos da fase de hidrólise. Na fase de hidrólise, foram coletadas amostras a cada 30 minutos;

d) Fase aeróbia: a coleta das amostras foi realizada em intervalos de 30 minutos e uma após 45 minutos como último ponto amostral.

\section{Interpretando o respirograma}

O software 3.2c do Beluga realiza a aquisição dos dados de leitura da TCO, OD e temperatura, que são plotadas diretamente em gráficos (respirograma), mostrando a leitura em tempo real. Esse equipamento foi utilizado para verificar as diferentes fases aplicadas nos ensaios com o lodo durante o processo de avaliação da remoção de fósforo.

A Figura 4 apresenta o respirograma gerado, mostrando o comportamento das variáveis OD e TCO que representam o metabolismo dos microrganismos envolvidos no processo de decomposição do esgoto bruto e do substrato sintético.

Tabela 1 - Parâmetros operacionais relevantes dos sistemas estudados

\begin{tabular}{|c|c|c|c|}
\hline Parâmetros & Reator 1 & Reator 2 & Reator 3 \\
\hline TRC (dias) & 20 & 5 & 3 \\
\hline Batelada $\left(\mathrm{dia}^{-1}\right)$ & 3 & 3 & 3 \\
\hline Volume útil (L) & 9 & 28,5 & 28,5 \\
\hline Volume de esgoto bruto tratado (L.dia ${ }^{-1}$ ) & 9 & 35,1 & 35,1 \\
\hline Descarte de lodo (L.dia-1) & 0,45 & 5,7 & 9,5 \\
\hline $\mathrm{OD}\left(\mathrm{mg} \mathrm{O}_{2} \cdot \mathrm{L}^{-1}\right)$ & $0,5-1,0$ & $0,5-1,2$ & $0,5-1,2$ \\
\hline Tempo de operação (dias) & 45 & 35 & 35 \\
\hline
\end{tabular}

TRC: tempo de retenção celular; OD: oxigênio dissolvido.

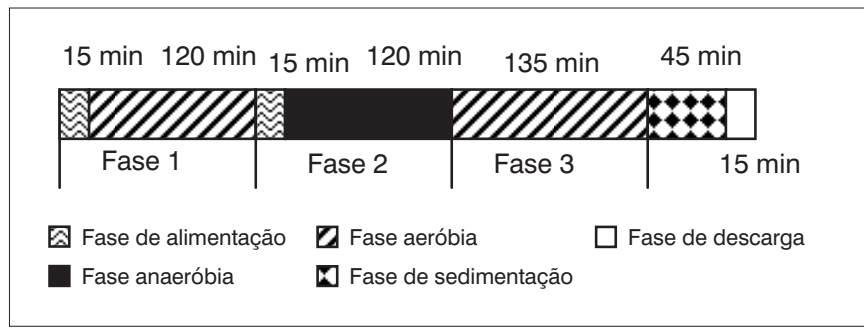

Figura 2 - Cronograma de um ciclo experimental utilizado no sistema R1

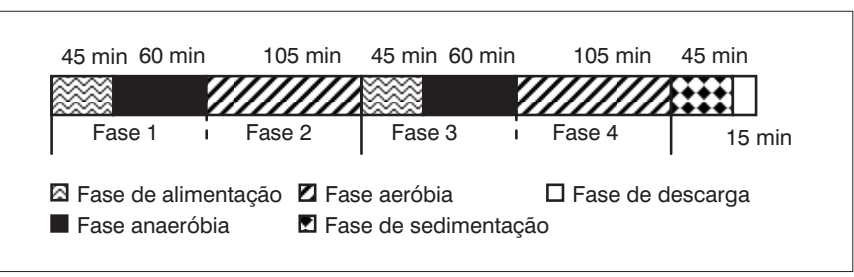

Figura 3 - Cronograma do ciclo experimental utilizado nos sistemas R2 e R3

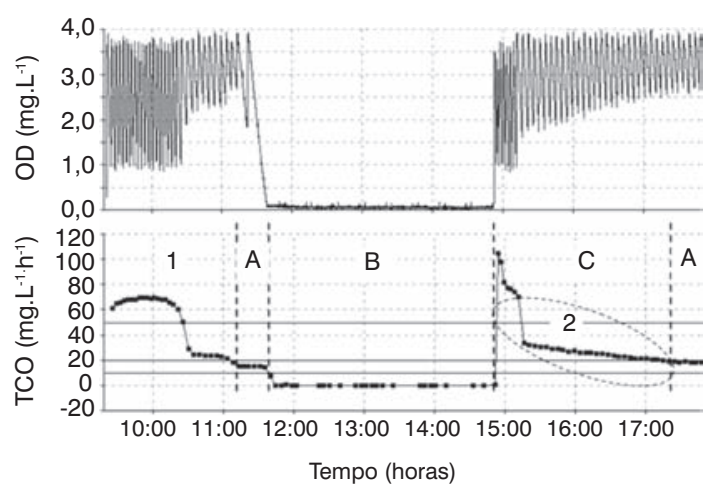

Onde:

1: período de adição do esgoto bruto

A: fase endógena

B: fase anaeróbia

C: fase aeróbia

2: fase de assimilação de P-PO43- e consumo de PHA

Figura 4 - Perfil de oxigênio dissolvido e taxa de consumo de oxigênio de uma amostra de lodo ativado utilizando o respirograma 
O teste respirométrico foi realizado em Becker de 2 L com adição de substrato sintético. O ensaio para o Rl foi realizado somente com o respirômetro, utilizando uma fase anaeróbia seguida de uma fase aeróbia, ambas com duração de três horas. Para os sistemas R2 e R3 foi realizado tanto o teste com respirometria quanto no sistema in loco.

\section{Resultados e discussão}

Os resultados dos parâmetros analisados nos reatores em bateladas sequenciais nos diferentes estudos estão apresentados na Tabela 2.

Os sistemas estudados não apresentaram variações de $\mathrm{pH}$ e temperatura que pudessem comprometer ou influenciar de forma expressiva o processo de tratamento aplicado, apresentando valores de $\mathrm{pH}$ próximos à neutralidade. A temperatura se manteve entre $24 \mathrm{e}$ $26^{\circ} \mathrm{C}$ para afluentes e efluentes.

$\mathrm{O}$ primeiro experimento com o Rl tratando esgoto bruto doméstico, durante o período de 45 dias, apresentou boa remoção de fosfato (81\%) associada à remoção de material carbonáceo (83\%) e considerável remoção de Nitrogênio Total Kjeldhal (NTK) (83\%).

A concentração de sólidos suspensos voláteis (SSV) no licor misto para o experimento no Rl variou entre 1.240 e $4.100 \mathrm{mg} \cdot \mathrm{L}^{-1}$. Menores variações foram encontradas no experimento R3, com mínimo de 390 e máximo de $1080 \mathrm{mgSSV}^{-1}$. Teoricamente, quanto mais alta a concentração de sólidos em suspensão do licor misto no tanque de aeração, maior é a eficiência do processo, removendo maiores concentrações de DQO e nutrientes disponível (STENSEL, 1991). Sidat, Kasan e Bux (1999) afirmam que o decaimento da população de bactérias poli-P reflete na diminuição da eficiência da remoção biológica de fósforo em excesso.

O decréscimo de SSV, nos sistemas estudados, está relacionado com a fração de lodo de descarte. Isso se deve ao fato de que a geração de novas bactérias poli-P foi inferior à retirada de biomassa do sistema durante o descarte de lodo. Esse comportamento se repetiu nos demais experimentos, entretanto, foi mantida durante todo o período uma boa remoção de fósforo (em torno de 80\%).

Brdjanovic et al (1998) investigaram um modelo para predizer o tempo mínimo de retenção celular em sistemas de remoção biológica de fósforo e concluíram que o processo não está limitado por um TRC mínimo, que é o resultado da taxa máxima de crescimento dos organismos, e sim porque o TRC da fase aeróbia deve ser bastante longo para oxidar a quantidade de PHA armazenada na fase anaeróbia. Isso significa que o TRC mínimo requerido dependerá principalmente da conversão cinética de PHA e do teor máximo possível de PHA armazenado no interior da célula durante a fase anaeróbia.

Os três experimentos realizados quanto à remoção biológica de fósforo não apresentaram diferença significativa ao nível de 5\% de probabilidade (ANOVA). O experimento com o R2 foi operado por um período de 35 dias, apresentando o sistema de maior remoção de fósforo, com eficiência para fósforo total e ortofosfato de 82 e 81\%, respectivamente.

A remoção de nitrogênio por nitrificação-desnitrificação foi mais acentuada no experimento R1 associado com o TRC de 20 dias, idade de lodo suficiente para que ocorra a nitrificação e, por conseguinte, a desnitrificação. Os reatores R2 e R3 foram operados com TRC mais baixos, de cinco e três dias, considerados insuficientes para completa nitrificação do material nitrogenado afluente. A não-oxidação desse material nitrogenado acarreta um efluente com consideráveis concentrações de nitrogênio amoniacal.

\section{Respirometria da biomassa do R1}

Com o lodo de descarte do sistema R1, foram realizados ensaios de liberação e assimilação de fósforo (Figura 5) com adição de fontes externas de carbono. No ensaio, foram adicionadas solução de acetato equivalente a $240 \mathrm{mgDQO} \cdot \mathrm{L}^{-1}$ e $18 \mathrm{mg} \cdot \mathrm{L}^{-1}$ de fósforo em solução.

Tabela 2 - Valores médios das variáveis analisadas nos afluentes e efluentes e eficiências médias obtidas, utilizando-se esgoto doméstico bruto

\begin{tabular}{|c|c|c|c|c|c|c|c|c|c|}
\hline Parâmetros & $\mathrm{EB}_{1}$ & R1 & ER (\%) & $\mathrm{EB}_{2}$ & $\mathrm{R} 2$ & ER (\%) & $\mathrm{EB}_{3}$ & $\mathrm{R} 3$ & ER (\%) \\
\hline$n$ & 25 & 25 & - & 14 & 14 & - & 8 & 8 & - \\
\hline $\mathrm{pH}$ & 7,55 & 7,86 & - & 7,13 & 7,56 & - & 6,9 & 7,54 & - \\
\hline Temperatura $\left({ }^{\circ} \mathrm{C}\right)$ & 24,8 & 24,4 & - & 25,2 & 25,5 & - & 24,9 & 25,3 & - \\
\hline$P_{\text {total }}\left(m g \cdot L^{-1}\right)$ & 6,6 & 1,4 & 79 & 8,7 & 1,6 & 82 & 9,1 & 1,92 & 79 \\
\hline $\mathrm{P}^{-\mathrm{PO}_{4}{ }^{3-}\left(\mathrm{mg} \cdot \mathrm{L}^{-1}\right)}$ & 4,8 & 0,9 & 81 & 5,9 & 1,1 & 81 & 5,83 & 1,61 & 72 \\
\hline $\mathrm{DQO}_{\mathrm{t}}\left(\mathrm{mgO}_{2} \cdot \mathrm{LL}^{-1}\right)$ & 426 & 73 & 83 & 487 & 57 & 88 & 552 & 74 & 87 \\
\hline $\mathrm{DQO}_{\mathrm{f}}\left(\mathrm{mgO}_{2} \cdot \mathrm{L}-1\right)$ & 159 & 54 & 66 & 221 & 51 & 77 & 186 & 52 & 72 \\
\hline $\mathrm{ALC}_{\mathrm{t}}\left(\mathrm{mg} \cdot \mathrm{CaCO}_{3} \cdot \mathrm{L}^{-1}\right)$ & 508 & 330 & - & 415 & 283 & - & 366 & 314 & - \\
\hline AGV (mg.HAc. $\left.L^{-1}\right)$ & 113 & 18 & - & 109 & 19 & - & 104 & 26 & - \\
\hline NTK (mg.L-1) & 48 & 8 & 83 & 64 & 21 & 67 & 74 & 47 & 36 \\
\hline $\mathrm{N}-\mathrm{NH}_{4}{ }^{+}\left(\mathrm{mg} \cdot \mathrm{L}^{-1}\right)$ & 39 & 7 & 82 & 50 & 18 & 64 & 55 & 40 & 27 \\
\hline $\mathrm{N}-\mathrm{NO}_{2}-\left(\mathrm{mg} \cdot \mathrm{L}^{-1}\right)$ & nd & 2,3 & - & nd & 2,7 & - & nd & 1,8 & - \\
\hline $\mathrm{N}-\mathrm{NO}_{3}-\left(\mathrm{mg} \cdot \mathrm{L}^{-1}\right)$ & nd & 9,1 & - & nd & 3,5 & - & nd & 1,6 & - \\
\hline $\operatorname{SSV}_{\mathrm{LM}}\left(\mathrm{mg} \cdot \mathrm{L}^{-1}\right)$ & - & 2.851 & - & - & 1.475 & - & - & 710 & - \\
\hline $\mathrm{SSV}_{\mathrm{Ef}}\left(\mathrm{mg} \cdot \mathrm{L}^{-1}\right)$ & 101 & 7 & - & 156 & 8 & - & 172 & 5 & - \\
\hline
\end{tabular}

n: número de determinações; EB: esgoto doméstico bruto; R1, R2 e R3: reatores 1, 2 e 3; nd: não-determinado; ER: eficiência de remoção; LM: licor misto; Ef: efluente; DQO: demanda química de oxigênio total; $\mathrm{DQO}_{4}$ : demanda química de oxigênio filtrada; ALC,: alcalinidade total; AGV: ácidos graxos voláteis; NTK: nitrogênio total Kjeldahl; SSV: sólidos suspensos voláteis. 
O respirograma mostra o comportamento do ensaio desde a decomposição do esgoto bruto afluente até o final do teste com fonte externa de carbono (Figura 5A). O ensaio teve duração de seis horas, sendo três horas para a fase anaeróbia e três horas para a fase aeróbia. A TCO média da fase endógena foi de $23 \mathrm{mgO}_{2} \cdot \mathrm{L}^{-1} \cdot \mathrm{h}^{-1}$. É importante iniciar o ensaio identificando corretamente a fase endógena para que, após a fase anaeróbia e aeróbia, não surjam concentrações indesejáveis de nitrato e a TCO apresente valores próximos as do início do ensaio, caracterizando tão somente o consumo do material orgânico armazenado (PHA) pelas bactérias poli-P.

$\mathrm{Na}$ fase endógena, a concentração de ortofosfato foi de 0,35 mgP- $\mathrm{PO}_{4}{ }^{3-} \cdot \mathrm{L}^{-1}$ e a de nitrato de 8,64 $\mathrm{mgN}^{-\mathrm{NO}_{3}}{ }^{-} \mathrm{L}^{-1}$ com DQO de $82 \mathrm{mgO}_{2} \cdot \mathrm{L}^{-1}$. Com a adição de fósforo e DQO solúvel, no ambiente anaeróbio, foi verificada a assimilação de DQO tanto para realizar o processo de desnitrificação quanto para a liberação de fosfato para o meio líquido. Em praticamente uma hora de teste, todo o nitrato foi removido e a liberação máxima de fósforo foi alcançada, chegando à concentração aproximada de $59 \mathrm{mgP}-\mathrm{PO}_{4}^{3-} \cdot \mathrm{L}^{-1}$ (Figura 5B).

$\mathrm{Na}$ fase aeróbia, foi mantida uma concentração de OD no meio líquido entre 1 e $3 \mathrm{mgO}_{2} \cdot \mathrm{L}^{-1}$. Nessa fase, ocorreu a assimilação do fósforo liberado na fase anaeróbia e, simultaneamente, a assimilação em

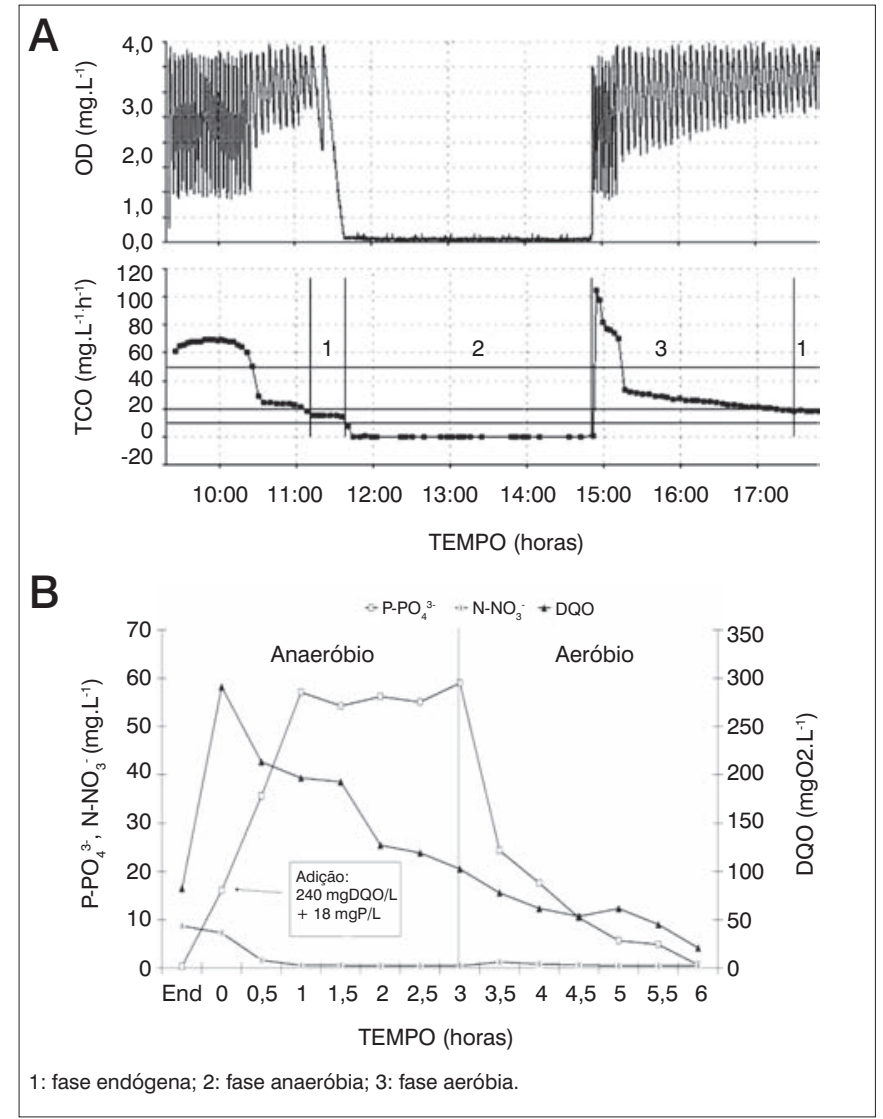

Figura 5 - (A) Perfil da concentração de oxigênio dissolvido e taxa de consumo de oxigênio por meio da respirometria; (B) perfil da concentração de $\mathrm{P}_{-} \mathrm{PO}_{4}{ }^{3-}, \mathrm{N}_{-} \mathrm{NO}_{3}{ }^{-}$e demanda química de oxigênio das amostras coletadas durante 0 ensaio com a biomassa do R1, com adição de fósforo, no início do teste excesso do fósforo adicional, luxury uptake, chegando a remover prati-

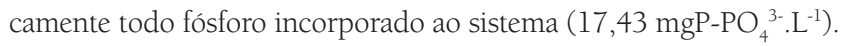

O lodo utilizado nesse ensaio apresentou concentração de 4.100 mgSSV.L $\mathrm{L}^{-1}$ e aproximadamente $485 \mathrm{mgP.L}^{-1}$, o que corresponde a uma relação de 0,118 mgP.mgSSV ${ }^{-1}$. Wang et al (2008), utili-

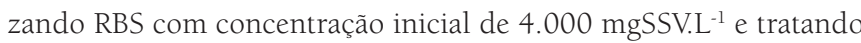
esgoto sintético com $400 \mathrm{mg} \cdot \mathrm{L}^{-1}$ de $\mathrm{DQO}_{\mathrm{rb}}$ e aproximadamente 20 mgP.L ${ }^{-1}$, obtiveram resultados satisfatórios de 98,6\% de remoção total de fósforo.

\section{Respirometria da biomassa do Reator 2}

Na Figura 6, está apresentado o comportamento quanto à liberação e assimilação de fósforo utilizando a biomassa do Reator 2 (R2). Para esse ensaio, levou-se em consideração a aplicação de duas fases anaeróbias seguidas de duas fases aeróbias. Essa metodologia foi aplicada em comparação ao sistema in loco, conferindo-se o mesmo comportamento no momento dos ensaios de laboratório.

A distribuição da alimentação em duas etapas foi proposta com a in-

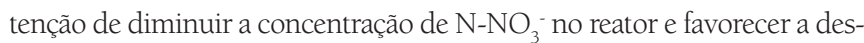
nitrificação na $1^{\mathrm{a}}$ etapa, mantendo uma DQO acessível na fase anaeróbia para proporcionar o armazenamento de PHA pelas bactérias poli-P.

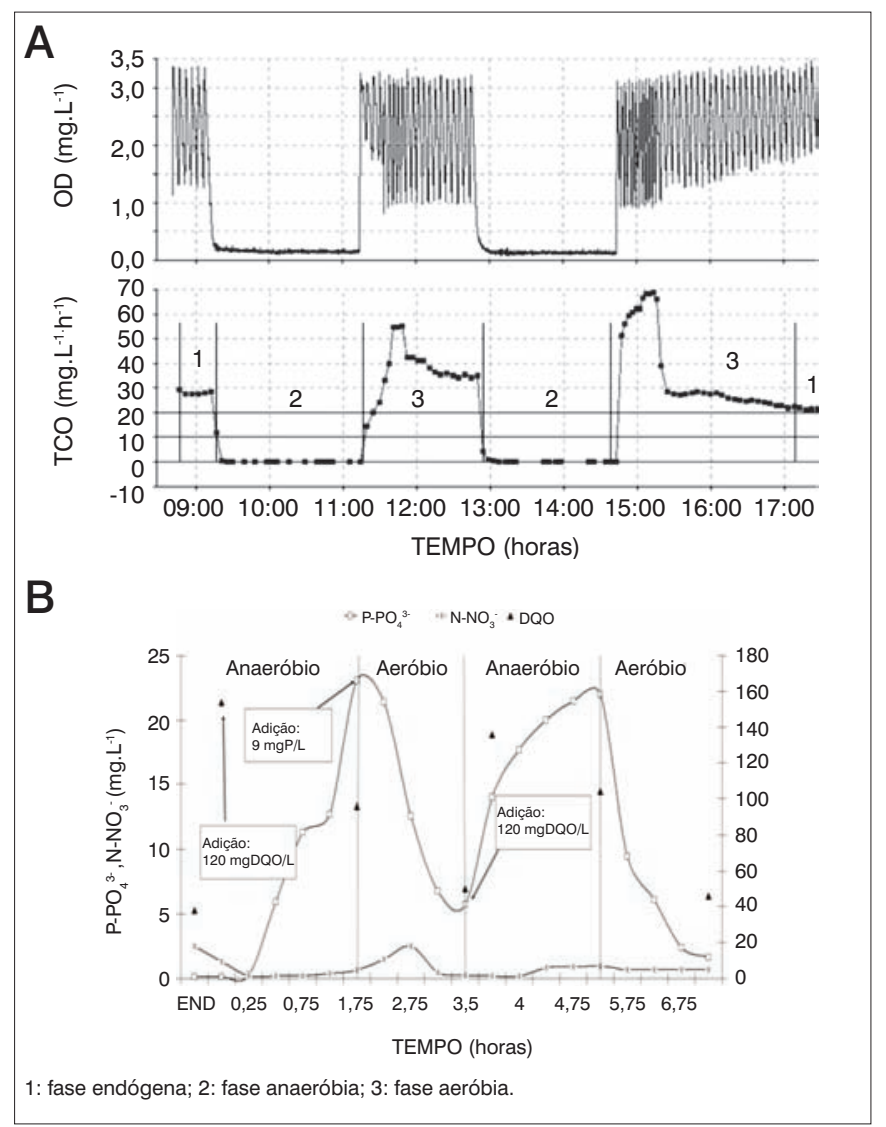

Figura 6 - (A) Perfil da concentração de oxigênio dissolvido e taxa de consumo de oxigênio por meio da respirometria; (B) perfil da concentração de $\mathrm{P}_{-} \mathrm{PO}_{4}{ }^{3-}, \mathrm{N}_{-} \mathrm{NO}_{3}{ }^{-}$e demanda química de oxigênio das amostras coletadas durante 0 ensaio com a biomassa do R2, com adição de fósforo, no início da fase aeróbia 
Akin e Ugurlu (2004) estudaram o efeito de uma zona anóxica na remoção biológica de fósforo em RBS. O sistema foi operado com $4.000 \mathrm{mgSSV} . \mathrm{L}^{-1}$, TRC de 25 dias e, tratando efluente sintético (400 mgDQO.L-1, 21 mgP.L-1 e 53 mgN-NH${ }_{4} \cdot L^{-1}$ ), obtiveram remoção de aproximadamente $80 \%$ de $\mathrm{P}_{-} \mathrm{PO}_{4}^{3-}, 98 \%$ de $\mathrm{N}_{-} \mathrm{NH}_{4}$ e $97 \%$ de $\mathrm{DQO}$, no entanto, o sistema foi ineficiente na remoção de nitrato, apresentando concentrações no efluente final entre 34 e $41 \mathrm{mgN}-\mathrm{NO}_{3} \mathrm{~L}^{-1}$.

Zou et al (2006) estudaram o papel do nitrato na remoção biológica de fósforo em RBS e comprovaram que o nitrato pode ser utilizado como aceptor de elétrons, na remoção de fosfato. Mostraram também que o nitrato adicionado na fase aeróbia tanto favoreceu a remoção de fosfato como de nitrato. Em sua investigação, Zou et al (2006) observaram que maior remoção de fosfato (96\%) foi alcançada em condições aeróbias (oxigênio), e usando nitrato como aceptor obteve-se $87,1 \%$ de remoção de fosfato.

$\mathrm{Na}$ respiração endógena, a TCO foi de aproximadamente 27 $\mathrm{mgO}_{2} \cdot \mathrm{L}^{-1} \cdot \mathrm{h}^{-1}$ em média (Figura $6 \mathrm{~A}$ ), e a concentração de fósforo atingiu $0,1 \mathrm{mgP}-\mathrm{PO}_{4}{ }^{3-} \cdot \mathrm{L}^{-1}$, com concentração de $38 \mathrm{mg}$.DQO.L ${ }^{-1}$ e baixa concentração de nitrato $\left(2,5 \mathrm{mgN}-\mathrm{NO}_{3} \cdot \mathrm{L}^{-1}\right)$, conforme apresentado na Figura 6B. A baixa concentração de nitrato no início dos ensaios é relevante, pois diminui a concorrência por material orgânico

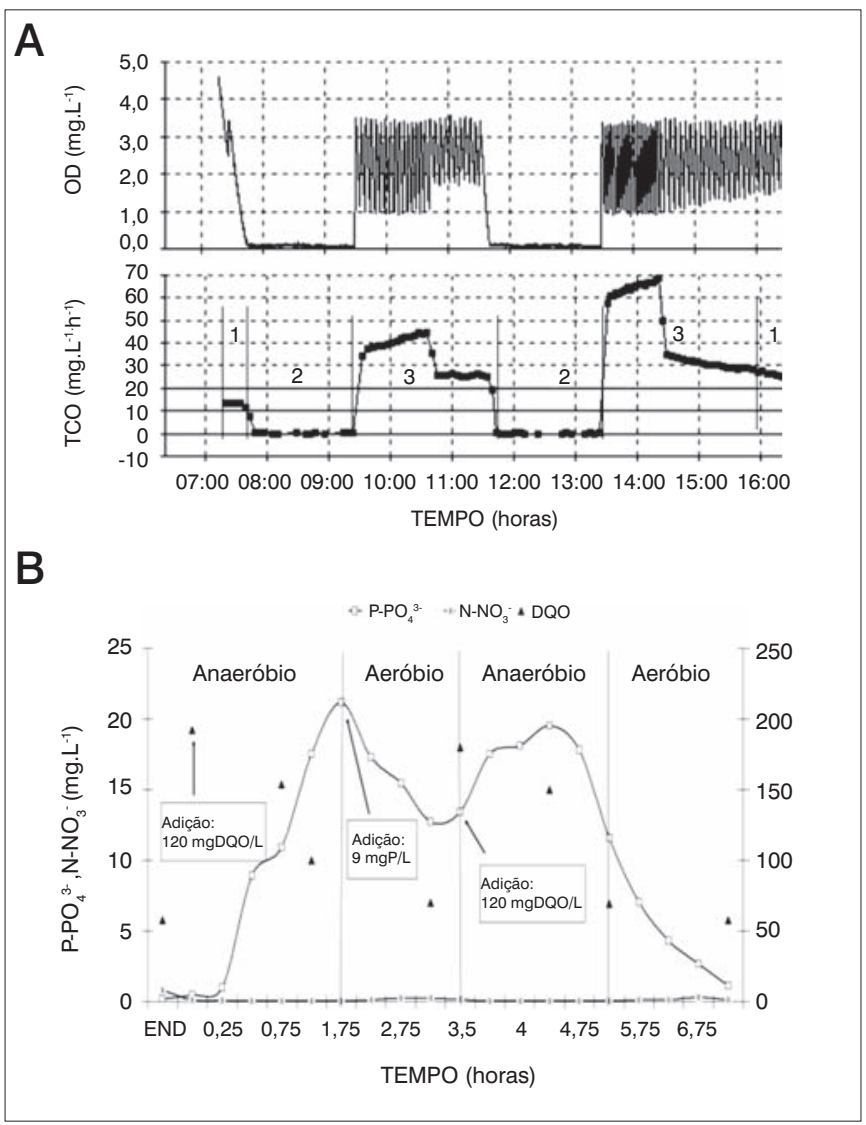

Figura 7 - (A) Perfil da concentração de oxigênio dissolvido e taxa de consumo de oxigênio por meio da respirometria; (B) perfil da concentração de $\mathrm{P}_{-} \mathrm{PO}_{4}{ }^{3-}, \mathrm{N}_{-} \mathrm{NO}_{3}{ }^{-}$e demanda química de oxigênio das amostras coletadas durante 0 ensaio com a biomassa do R3, com adição de fósforo, no início da fase aeróbia rapidamente biodegradável, substrato importante para o processo de remoção de fósforo pelas bactérias poli-P.

Observa-se, ainda na Figura 6B, que, ao final da primeira fase anaeróbia, foram liberados $14,06 \mathrm{mg} . \mathrm{L}^{-1}$ de fósforo, atingindo concentração máxima no reator de 23,06 mgP- $\mathrm{PO}_{4}^{3-} \cdot \mathrm{L}^{-1}$. Ao término da $1^{\text {a }}$ fase aeróbia, a concentração final de fósforo foi de $5,74 \mathrm{mg} \cdot \mathrm{L}^{-1}$, proporcionando a redução de 3,26 mgP-PO ${ }_{4}^{3-} \cdot \mathrm{L}^{-1} 1$ do fósforo adicional. Após o término da segunda etapa, essa remoção foi de $8,37 \mathrm{mg} \cdot \mathrm{L}^{-1}$ do fósforo adicional, mantendo o efluente final com concentrações de fosfato abaixo de $2 \mathrm{mgP}-\mathrm{PO}_{4}^{3-} \cdot \mathrm{L}^{-1}$

Quanto maior for a relação mgP.mgSSV ${ }^{-1}$, maior será a concentração de fósforo por biomassa ativa, indicando a presença de bactérias poli-P. A biomassa do R2 apresentou uma concentração de SSV e $\mathrm{P}_{\text {total }}$ de 1.400 e $176,5 \mathrm{mg} \cdot \mathrm{L}^{-1}$, respectivamente, representando uma relação mgP.mgSSV ${ }^{-1}$ de 0,126 .

\section{Respirometria da biomassa do Reator 3}

A Figura 7 apresenta o comportamento da biomassa do sistema no Reator 3 (R3). Esse ensaio foi idêntico ao realizado no experimento com a biomassa do R2.

A Figura 7A mostra a TCO endógena com concentrações médias de $13 \mathrm{mgO}_{2} \cdot \mathrm{L}^{-1} \cdot \mathrm{h}^{-1}$ e concentrações de fosfato de $0,2 \mathrm{mgP}-\mathrm{PO}_{4}{ }^{3-} \cdot \mathrm{L}^{-1}$ (Figura 7B). Nessa fase, a DQO encontrada foi de $58 \mathrm{mgO}_{2} \cdot \mathrm{L}^{-1} \mathrm{com}$ baixíssima concentração de nitrato $\left(0,81 \mathrm{mgN}-\mathrm{NO}_{3}{ }^{-} \cdot \mathrm{L}^{-1}\right)$.

A concentração de fósforo no meio líquido ao final da $1^{\text {a }}$ fase anaeróbia foi de aproximadamente $20 \mathrm{mgP}-\mathrm{PO}_{4}{ }^{3-} \cdot \mathrm{L}^{-1}$.

Como pode ser observado na Figura 7B, a repetição da fase anaeróbia foi de grande importância, pois a maior concentração de fósforo foi removida na $2^{\text {a }}$ fase, evidenciando a necessidade do sistema por material orgânico rapidamente biodegradável. Ao final do ensaio, verificouse que a luxury uptake foi de aproximadamente $8 \mathrm{mgP}-\mathrm{PO}_{4}{ }^{3-} \cdot \mathrm{L}^{-1}$

Com tempo de retenção celular muito baixo (três dias) é retirada uma concentração alta de sólidos em suspensão pelo descarte de lodo, o qual provoca decréscimo acentuado da biomassa ativa. É importante apontar que a concentração de SSV do lodo para este teste foi considerada baixa (790 mgSSV.L ${ }^{-1}$ ), com concentração de 89,5 mgP-PO ${ }_{4}^{-3} \cdot \mathrm{L}^{-1}$, apresentando valor de $0,113 \mathrm{mgP} \cdot \mathrm{mgSSV}{ }^{-1}$.

\section{Perfil da concentração de DQO rapidamente biodegradável $\left(\mathrm{DQO}_{\mathrm{rb}}\right)$ do esgoto bruto}

A DQO total $\left(\mathrm{DQO}_{\mathrm{t}}\right)$ média do esgoto bruto nas três fases experimentais $\left(E_{1}, E_{2}\right.$ e $E_{3}$ ) apresentou valores considerados de 426, 487 e $552 \mathrm{mgO}_{2} . \mathrm{L}^{-1}$, respectivamente, conforme Tabela 2. Entretanto, nem toda fração de $\mathrm{DQO}_{\mathrm{t}}$ encontrada era rapidamente biodegradável. Esta afirmativa se deu através de testes realizados com a biomassa ativa e o esgoto bruto (Figura 8). Para determinar a $\mathrm{DQO}_{\mathrm{rb}}$ do esgoto bruto, foi necessário aplicar uma solução de Allylthiourea (ATU), uma substância orgânica com propriedades seletivas de inibir a oxidação da amônia pelas bactérias nitrificantes (GINESTET et al, 1998). 
Com o uso do respirômetro, foi possível detectar que a fração de $\mathrm{DQO}_{\mathrm{rb}}$ era muito baixa, chegando a valores entre 6 e 10\% da $\mathrm{DQO}_{\mathrm{t}}$, corroborando uma concentração de $\mathrm{DQO}_{\mathrm{rb}}$ limitante.

Van Haandel e Marais (1999) mostram que a exposição do lodo a um ambiente anaeróbio é uma condição necessária, mas não suficiente para que ocorram os processos de liberação e absorção de fósforo, além de afirmarem que a fração de fósforo no lodo ativo é influenciada pela concentração do material orgânico rapidamente biodegradável na zona anaeróbia. Entende-se que a baixa concentração desse material rapidamente biodegradável implica baixa eficiência no processo de remoção de fósforo.

Chiou e Yang (2008), variando a concentração de DQO afluente (100-500 $\mathrm{mgO}_{2} \cdot \mathrm{L}^{-1}$ ), buscaram investigar o processo de estocagem de PHA pela bactérias poli-P, relacionando-o à assimilação de fosfato do meio líquido, e provaram que a DQO limitou o armazenamento de PHA e, consequentemente, diminuiu a remoção de fosfato. Isso afirma, em outras palavras, que a limitação para a capacidade de armazenamento de fósforo sempre acontece durante a fase anaeróbia, e não na fase aeróbia.

\section{Perfil in loco da biomassa dos reatores R2 e R3}

O teste realizado no próprio reator teve a finalidade de compreender o processo de remoção de fósforo, tratando esgoto bruto doméstico.

Diferente dos ensaios que utilizavam fonte externa de carbono em solução, na forma de acetato, os ensaios com amostras coletadas diretamente do sistema in loco tinham como fonte de carbono o próprio esgoto bruto doméstico e suas respectivas concentrações de fósforo e nitrogênio (Tabela 3).

A concentração inicial de nitrato $\left(0,8 \mathrm{mgN}-\mathrm{NO}_{3}{ }^{-} \cdot \mathrm{L}^{-1}\right)$ no sistema não comprometeu o processo de liberação de fósforo, que poderia ocorrer através da competição por $\mathrm{DQO}_{\mathrm{rb}}$ (Figura 9A). A liberação de fósforo, somada ao fósforo afluente na $1^{\text {a }}$ fase anaeróbia, foi de 8,4 $\mathrm{mgP}-\mathrm{PO}_{4}{ }^{3-} \cdot \mathrm{L}^{-1}$. A baixa liberação de fósforo na zona anaeróbia pode ser explicada pela baixa concentração de $\mathrm{DQO}_{\mathrm{rb}}$ no esgoto bruto; no entanto, não comprometeu a remoção de fósforo, uma vez que, ao final do ensaio, a concentração foi de 0,41 mgP-PO ${ }_{4}^{3-} \cdot \mathrm{L}^{-1}$.

No início da $2^{\text {a }}$ fase anaeróbia, foram detectados 4,42 mgN-NO. $L^{-1}$ e observou-se que a liberação de fósforo para esta etapa foi menor que na $1^{\text {a }}$ etapa, justificando a competição pelo substrato solúvel no processo de desnitrificação. A DQO ${ }_{t}$ remanescente foi de aproximadamente $40 \mathrm{mgO}_{2} \cdot \mathrm{L}^{-1}$.

As concentrações de SSV e $\mathrm{P}_{\text {total }}$ no lodo foi de $1.350 \mathrm{mgSSV}^{-1}$ e $133 \mathrm{mgP}-\mathrm{PO}_{4}^{3-} \cdot \mathrm{L}^{-1}$, respectivamente, apresentando uma relação de 0,099 mgP.mgSSV ${ }^{-1}$. Através dos resultados produzidos com a biomassa do R2, foi possível verificar a presença de bactérias poli-P, incorporando aproximadamente $10 \%$ de fósforo na biomassa ativa.

Mesmo com uma $\mathrm{DQO}_{\mathrm{rb}}$ limitante no EB, o sistema R3 com baixo TRC apresentou boa remoção de fósforo. A Figura 9B mostra que a liberação de fósforo não permaneceu constante ao término de cada uma das fases anaeróbias, entendendo-se que boa parte da $\mathrm{DQO}_{\mathrm{lb}}$ estava sendo hidrolisada e o fósforo continuava a ser liberado.

As concentrações de SSV (800 mg. $\left.\mathrm{L}^{-1}\right)$ e de fósforo total $(76,4$ mg..$\left.^{-1}\right)$ na biomassa representaram uma relação de 0,096 mgP.mgS$\mathrm{SV}^{-1}$ para o sistema R3.

Broughton, Pratt, Shilton (2008) propuseram avaliar a possibilidade de remoção de fósforo em escala de laboratório operando reator em bateladas com diferentes relações DQO:P; de 25:1, 15:1 e 10:1. Neste experimento, os pesquisadores utilizaram como fonte externa de carbono uma mistura de propianato e acetato de sódio. Os resultados mostraram que os sistemas operados com relação DQO:P de 25:1 e 15:1 apresentaram remoção completa de fósforo e, para a relação 10:1, o percentual de remoção foi de $82 \%$.

Os experimentos realizados com os sistemas R2 e R3 foram operados com relação média de $\mathrm{DQO}_{\mathrm{rb}}: \mathrm{P}$ de aproximadamente 8:1, confirmando uma remoção percentual de fósforo de 82 e 79\%, similar à encontrada por Broughton, Pratt e Shilton (2008).

\section{Conclusões}

A tecnologia de reatores em bateladas sequenciais com aeração intermitente é uma variável do sistema de lodo ativado convencional

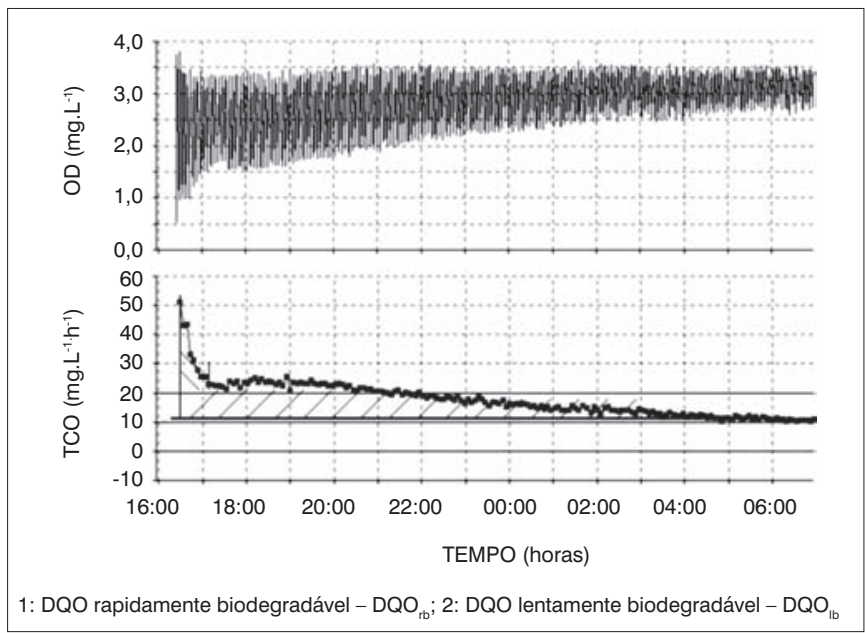

Figura 8 - Perfil da decomposição do esgoto bruto doméstico pelas bactérias heterotróficas na verificação da concentração da $\mathrm{DQO}_{\mathrm{rb}}$

Tabela 3 - Valores médios do esgoto bruto afluente aplicado nos sistemas R2 e R3

\begin{tabular}{|c|c|c|c|c|c|c|}
\hline Variável & $P_{\text {total }}\left(\mathrm{mg} \cdot \mathrm{L}^{-1}\right)$ & $\mathrm{P}-\mathrm{PO}_{4}{ }^{3-}\left(\mathrm{mg} \cdot \mathrm{L}^{-1}\right)$ & $\mathrm{DQO}_{\mathrm{t}}\left(\mathrm{mg} \cdot \mathrm{L}^{-1}\right)$ & $\mathrm{DQO}_{\mathrm{f}}\left(\mathrm{mg} \cdot \mathrm{L}^{-1}\right)$ & NTK (mg. L $\left.^{-1}\right)$ & $\mathrm{N}-\mathrm{NH}_{4}{ }^{+}\left(\mathrm{mg} \cdot \mathrm{L}^{-1}\right)$ \\
\hline $\mathrm{EB}-\mathrm{R} 2$ & 9,4 & 5,86 & 376 & 171 & 58,24 & 51,25 \\
\hline EB - R3 & 8,17 & 6,1 & 482 & 208 & 71,49 & 54,99 \\
\hline
\end{tabular}

DQO: demanda química de oxigênio total; DQO: demanda química de oxigênio filtrada; NTK: nitrogênio total Kjeldahl. 


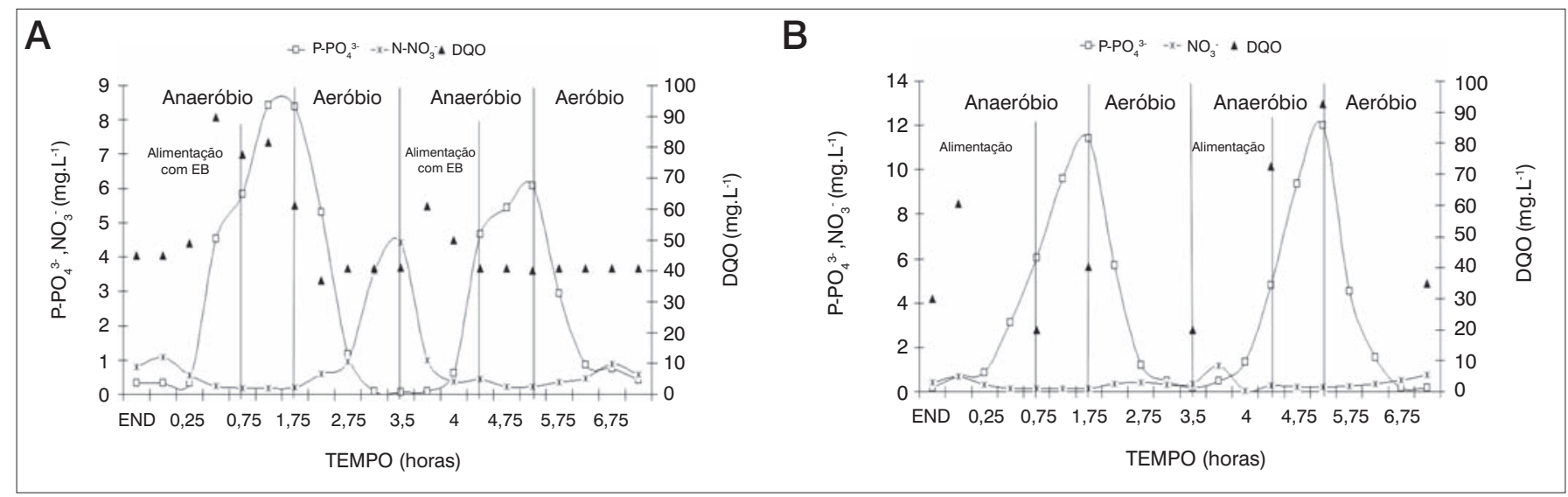

Figura 9 - Perfil da concentração de $\mathrm{P}_{-} \mathrm{PO}_{4}{ }^{3-}, \mathrm{N}_{-} \mathrm{NO}_{3}{ }_{3}^{-}$e demanda química de oxigênio das amostras coletadas durante 0 monitoramento do sistema R2 (A) e R3 (B), alimentado com esgoto bruto

que permite intercalar as fases anaeróbias e aeróbias, favorecendo as condições necessárias para o sucesso da remoção de fósforo.

A remoção biológica de fósforo foi alcançada nos três experimentos. No entanto, o sistema R2 monitorado com TRC de cinco dias apresentou os melhores resultados de remoção de fósforo total e ortofosfato com 82 e $81 \%$, respectivamente. Nos ensaios com substrato sintético, foi também o R2 que apresentou maiores relações mgP.mgSSV ${ }^{-1}$, com percentual de $12,6 \%$. Mesmo com maiores valores de remoção de fósforo no sistema R2, não houve diferença significativa $(p<0,05)$ entre os três experimentos.

Os resultados mostraram que a concentração de sólidos em suspensão nos reatores não foi o fator limitante no processo de remoção de fósforo; no entanto, a baixa disponibilidade da $\mathrm{DQO}_{\mathrm{rb}}$ (6 a 10\%) limitou a remoção biológica de fósforo.

\section{Referências}

AKIN, B.S.; UGURLU, A. The effect of an anoxic zone on biological phosphorus removal by a sequential batch reactor. Bioresource Technology, v. 94, n. 1, p. 1-7, 2004.

AMERICAN PUBLIC HEALTH ASSOCIATION (APHA). Standard methods for the examination of water and wastewater. 20th. Washington: Public Health Association, 1998.

BRDJANOVIC, D. etal. Minimal aerobic sludge retention time in biological phosphorus removal systems. Biotechnology \& Bioengineering. v. $60, n$. 3, p. 326-332, 1998.

BROUGHTON, A.; PRATT, S.; SHILTON, A. Enhanced biological phosphorus removal for high-strength wastewater with a low rbCOD:P ratio. Bioresource Technology, v. 99, n. 5, p 1236-1241, 2008.

CHIOU, R.; YANG, Y. An evaluation of the phosphorus storage capacity of an anaerobic/aerobic sequential batch biofilm reactor. Bioresource Technology, v. 99, n. 10, p. 4408-4413, 2008.

GINESTET, P. et al. Estimation of nitrifying bacterial activities by measuring oxygen uptake in the presence of the metabolic inhibitors allylthiourea and azide. Applied and Environmental Microbiology, v. 64, n. 6, p. 22662268, 1998

METCALF \& EDDY, Inc. Wastewater engineering: treatment and reuse. 4th ed. New York: McGraw-Hill, 2003.
SIDAT, M.; KASAN, H.C.; BUX, F. Laboratory-scale investigation of biological phosphate removal from municipal wastewater. Water $S A$, v. 25, n. 4, p. 459-462, 1999

STENSEL, H.D. Principles of biological phosphorus removal. In: SEDLAK, R.I. (Ed.). Phosphorus and nitrogen removal from municipal wastewater: principles and practice. 2nd ed. New York: Lewis Publishers, 1991. p. 141-163.

Van DER POST, D.C.; SCHUTTE, C.F. A proposed chemical mechanism for biological phosphate removal in activated sludge treatment of wastewater. Water SA, v. 29, n. 2, p. 125-128, 2003.

Van HAANDEL, A.C.; MARAIS, G.V.R. O comportamento do sistema de lodo ativado: teoria e aplicação para projeto e operação. Campina Grande: Epgraf, 1999.

WANG, D. et al. Biological Phosphorus removal in sequencing batch reactor with single-stage oxic process. Bioresource Technology, v. 99, n. 13, p. 5466-5473, 2008.

WENTZEL, M.C. et al. Enhanced polyphosphate organism culture in activated sludge systems. Part II: Experimental behaviour. Water $S A, v$. 15, n. 2, p. 71-88, 1989.

ZOU, $\mathrm{H}$. et al. Role of nitrate in biological phosphorus removal in a sequencing batch reactor. World Journal of Microbiology \& Biotechnology, v. 22, n. 7, p. 701-706, 2006 